\title{
Assessment of Knowledge, Attitude and Practices of Medical Officers in Primary Health Centres Regarding Type 2 Diabetes Mellitus
}

\author{
Jayaprakash S Appajigol, ${ }^{1}$ Manjunath Somappa Somannavar ${ }^{2}$
}

\begin{abstract}
:
Background: Health education is an integral part of Type 2 diabetes mellitus (T2DM) management, as it can be prevented and controlled by the implication of appropriate interventions. The aim of the study was to assess the knowledge, attitude, and practice (KAP) of medical officers (MOs) in primary health centres (PHC) regarding T2DM.

Materials and methods: The 104 medical officers (MOs) with an experience of $\leq 2$ years of medical practice were included in the study. A self-completion questionnaire, designed to be completed within 10-15 minutes, was developed to analyse the KAP of the MOs regarding T2DM.

Results: Among the 104 MOs, 14 had knowledge about the prevalence of T2DM in India. Among the risk factors, obesity (7I), physical inactivity (3I), family history (43), and hypertension (15) were identified by the MOs. The microvascular complications, including retinopathy (77), nephropathy (63), and neuropathy (49) were stated by the physicians. However, the physicians were less aware about the macrovascular complications. As few as 23 physicians included HbAlc test as one of the diagnostic methods, 43 physicians included $\mathrm{HbA} / \mathrm{c}$ to monitor the glycemic levels. More than half (55) of the physicians prescribed appropriate medications for the treatment of T2DM.

Conclusions: The MOs had considerable knowledge and attitude about T2DM, however due to lack of facilities at the PHCs, the practice of MOs in the management of T2DM is poor. Education programmes to expand the understanding of the MOs regarding T2DM and initiatives to advance the facilities at PHCs are essential to manage T2DM in India.
\end{abstract}

Keywords: Type 2 Diabetes Mellitus, Primary health care centre, Knowledge, Attitude, Practice, Medical officer.

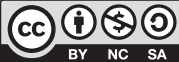

DOI: https://doi.org/I0.3329/jom.v20i2.42004

Copyright: (C) 2019 Appajigol JS et al. This is an open access article published under the Creative Commons Attribution-NonCommercial-NoDerivatives 4.0 International License, which permits use, distribution and reproduction in any medium, provided the original work is properly cited, is not changed in any way and it is not used for commercial purposes.

Received: 29 March, 2018;

Accepted: 23 July, 2018

\section{Introduction:}

Non-communicable diseases (NCDs) are the major challenges to sustainable human development in the $21^{\text {st }}$ century. ${ }^{1}$ Type 2 diabetes mellitus (T2DM) is one of the important NCD in developing countries, such as India, which experience major health burden. The diabetic population in

1. Associate Professor, Department of General Medicine, Jawaharlal Nehru Medical College, KLES University, Nehru Nagar, Belgaum-560010, Karnataka. India.

2. Associate Professor, Department of Biochemistry, Jawaharlal Nehru Medical College, KLES University, Nehru Nagar, Belgaum-560010, Karnataka. India.

Corresponding author: Dr. Jayaprakash S Appajigol, Associate Professor, Department of General Medicine, Jawaharlal Nehru Medical College, KLES University, Nehru Nagar, Belgaum-560010, Karnataka. India, E-mail: jayaprakashappajigol@gmail.com, Tel: +91-9844595659.
India was estimated to be around 31 million in 2000 and projected to cross 79 million by $2030 .^{2}$ In 2015 , the International Diabetes Federation (IDF) estimated that approximately 36 million adults in India were undiagnosed with diabetes. The change in the dietary patterns and lifestyle due to urbanization contribute to the long-term implications of diabetes. Due to delayed diagnosis or non-diagnosis, patients experience considerable burden of diabetes and associated comorbidities and complications, such as hypertension, obesity, and micro and macrovascular complications. ${ }^{3}$ Early diagnosis and management of diabetes can reduce the diabetes-associated complications. The primary aim of management of diabetes is to delay the micro and macrovascular complications by monitoring the blood glucose levels. ${ }^{4,5}$ Studies on pre-diabetic patients have shown that life style interventions involving weight loss 
can prevent the development of T2DM, therefore it is important to detect patients with pre-diabetes. 6,7

Health education is an integral part of diabetes management, as it can be prevented and controlled by implication of appropriate interventions. Evidence-based studies indicate that the physicians who practice and educate patients regarding the interventions, such as regular exercise, weight loss, and drug therapy achieve better and durable diabetic control in the patients. Physicians with good knowledge of these attributes can prevent the development of prediabetes to diabetes. The assessment of knowledge, attitude, and practice (KAP) aids in analysing the gap between the physicians' knowledge and current evidence-based interventions and developments which are useful in the prevention, management, and control of diabetes.

Although, many KAP studies have been conducted on patients, there is a dearth of literature in analysing the understanding of physicians and primary healthcare medical officers (MOs) regarding type 2 diabetes mellitus (T2DM). To our knowledge, the present study is one of the first studies in India to evaluate the knowledge, attitude, and practices of MOs in the primary healthcare centres (PHCs) regarding T2DM. Identification and assessment of knowledge, attitude, and practice of MOs in rural PHCs will provide better insight for improving the health literacy in the PHCs.

\section{Materials and methods:}

\section{Sampling and study design}

This cross-sectional study was conducted in PHCs in three districts of North Karnataka. A total of 104 primary care physicians appointed by the Health and Family Welfare Department, designated as MO working in the rural PHCs were included in the study. The MOs with an experience of $\leq 2$ years of medical practice were included in the study.

\section{Procedure}

A self-completion questionnaire, designed to be completed within 10-15 minutes, was developed to analyse the KAP of the MOs regarding T2DM. After thorough review of literature, the questionnaire was developed and validated by five MOs for scope, length, and clarity.

\section{Data collection and statistical analysis}

Before commencement of the study, the ethical clearance was obtained from the MOs. After explaining the purpose of the study, written consent was obtained from the MOs and the questionnaire was provided. The completed questionnaires were manually checked and coded before data entry. The data were analysed by simple frequency counts.
Results:

\section{Knowledge}

The physicians' knowledge towards T2DM revealed that 14 participants were aware about the prevalence of T2DM in India. Obesity, physical inactivity, family history, and hypertension were identified as risk factors for T2DM by 71 , 31,43 , and 15 physicians, respectively. However, only 10 physicians had knowledge of obesity, physical inactivity, and family history as combined risk factors in the development of T2DM.

Most of the physicians were aware of the symptoms of T2DM, such as polyurea (89), polydipsia (80), and polyphagia (66). However, only 59 physicians stated all the three symptoms of T2DM. Weight loss, an important symptom of T2DM, was identified by 14 physicians. The diagnostic plasma glucose levels, as stated by the American Diabetes Association (ADA), for detecting T2DM and pre-diabetes were known by only 3 and 2 physicians, respectively.

The physicians were also assessed regarding the macro and microvascular complications of T2DM. The microvascular complications, including retinopathy, nephropathy, and neuropathy were stated by 77, 63, and 49 physicians, respectively. However, the physicians were less aware about the macrovascular complications, including ischemic heart disease (51), cerebrovascular disease (11), and peripheral vascular disease (23). Only 1 physician had knowledge about all the macrovascular complications. Diabetic ketoacidosis was identified as a complication of T2DM by 9 physicians.

Therapeutic and non-therapeutic interventions involved in the treatment of T2DM were analysed. Lifestyle modifications were identified by 52 physicians as the nontherapeutic intervention. Therapeutic management of T2DM, including metformin, sulfonyl urea, and insulin were identified by 30, 31, and 52 physicians. Less than half(45) of the physicians were unaware of the therapeutic management of T2DM, of which 19 were unaware of the lifestyle modifications. The other classes of drugs, such as dipeptidyl peptidase-4 inhibitors (DPP) and glucagon-like peptide (GLP)-1 analogues were not stated by any of the physicians for the treatment of T2DM.

\section{Attitude}

The response of MOs towards the attitude questionnaire of T2DM are as shown in Table I. Most (80) of the physicians were aware of the fact that the prevalence of T2DM is more in developing countries than in the developed countries. Almost, 90 physicians believed that monitoring of glycosylated haemoglobin (HbAlc) and health education are beneficial for better glycemic control. Importance of strict glycemic control and diet and exercise were mentioned by 84 and 93 physicians, respectively. Treatment of T2DM with insulin therapy was considered easy by less than half of the physicians. 
Table I. Response of medical officers to the attitude questionnaire

\begin{tabular}{|c|c|c|c|c|c|c|c|}
\hline Sl. No. & Questions & $\begin{array}{c}\text { Strongly } \\
\text { Disagree } \\
\mathrm{n}(\%)\end{array}$ & $\begin{array}{c}\text { Disagree } \\
\mathrm{n}(\%)\end{array}$ & $\begin{array}{c}\text { Neutral } \\
\mathrm{n}(\%)\end{array}$ & $\begin{array}{c}\text { Agreen } \\
\mathrm{n}(\%)\end{array}$ & $\begin{array}{c}\text { Strongly } \\
\text { Agree } \\
n(\%)\end{array}$ & $\begin{array}{l}\text { Don't } \\
\text { know } \\
\mathrm{n}(\%)\end{array}$ \\
\hline 1 & $\begin{array}{l}\text { Prevalence of diabetes is increasing in developing } \\
\text { countries more than developed countries }\end{array}$ & $2(1.92)$ & $9(8.65)$ & $5(4.81)$ & $49(47.12)$ & $31(29.81)$ & $8(7.69)$ \\
\hline 2 & $\begin{array}{l}\text { Educating the patients about their disease will } \\
\text { help in better glycemic control }\end{array}$ & $2(1.92)$ & $0(0)$ & $0(0)$ & $58(55.77)$ & $36(34.62)$ & $8(7.69)$ \\
\hline 3 & $\begin{array}{l}\mathrm{HbA} 1 \mathrm{c} \text { monitoring is the best way for assessing } \\
\text { the glycemic control }\end{array}$ & $2(1.92)$ & $1(0.96)$ & $3(2.88)$ & $49(47.12)$ & $41(39.42)$ & $8(7.69)$ \\
\hline 4 & $\begin{array}{l}\text { Complications of diabetes can be prevented by } \\
\text { strict glycemic control }\end{array}$ & $1(0.96)$ & $8(7.69)$ & $3(2.88)$ & $50(48.08)$ & $34(32.69)$ & $8(7.69)$ \\
\hline 5 & $\begin{array}{l}\text { Diet and exercise are the integral part } \\
\text { of diabetes management }\end{array}$ & $3(2.88)$ & $0(0.0)$ & $0(0.0)$ & $44(42.31)$ & $49(47.12)$ & $8(7.69)$ \\
\hline 6 & $\begin{array}{l}\text { Insulin therapy is the difficult method of } \\
\text { treatment in our setting }\end{array}$ & $8(7.69)$ & $33(31.73)$ & $9(8.65)$ & $35(33.65)$ & $11(10.58)$ & $8(7.69)$ \\
\hline
\end{tabular}

\section{Practice}

The assessment of practices of MOs towards T2DM are summarised in Table II. Most (72) of the physicians were aware of the standard diagnostic tests for detecting T2DM. Urine sugar testing was the most commonly (54) followed test, followed by random blood sugar (RBS; 54), fasting plasma glucose (FPG; 47), and post-prandial plasma glucose (PPG; 47). Although, as few as 23 physicians included HbA1c test as one of the diagnostic methods, 43 physicians monitored the glycaemic levels by HbAlc. Other tests used to monitor T2DM included urine glucose (28), FPG (22), PPG (22), and RBS (19). Dietary modifications, such as reducing the consumption of simple carbohydrates to control the glycemic levels were advised by 60 physicians.

More than half (55) of the physicians prescribed appropriate medications for the treatment of T2DM. Insulin therapy was the most commonly (38) used mode of treatment, followed by sulfonylureas (34), metformin (27), and glitazones (10). The frequency of monitoring HbA1c levels varied from 3-6 months among 49 physicians. Few (16) of the physicians were not aware of monitoring $\mathrm{HbAlc}$ frequently. Annual monitoring of microalbuminuria levels was done by 3 physicians, whereas lipid profile was monitored by 16 physicians.

Table II. Response of medical officers to practice questionnaire

\begin{tabular}{|c|c|c|c|c|}
\hline S1. No. & Questions & $\begin{array}{c}\text { Correct } \\
\text { Answers } \\
\mathrm{n}(\%)\end{array}$ & $\begin{array}{c}\text { Did not } \\
\text { Answer } \\
\text { n }(\%)\end{array}$ & $\begin{array}{c}\text { Incorrect } \\
\text { Answer } \\
\mathrm{n}(\%)\end{array}$ \\
\hline 1 & What test you recommend for diagnosing diabetes? & $72(69.23)$ & $11(10.58)$ & $21(20.19)$ \\
\hline 2 & What test you recommend for monitoring of diabetes? & $45(43.27)$ & $12(11.54)$ & $47(45.19)$ \\
\hline 3 & What are the diet modifications you advise for diabetes patients? & $60(57.69)$ & $13(12.6)$ & $31(29.81)$ \\
\hline 4 & How frequently you monitor $\mathrm{HbA} 1 \mathrm{c} ?$ & $49(47.12)$ & $16(15.38)$ & $39(37.5)$ \\
\hline 5 & $\begin{array}{l}\text { What are the different classes of medications you use for the } \\
\text { treatment of diabetes? }\end{array}$ & $13(12.5)$ & $49(47.12)$ & $42(40.38)$ \\
\hline 6 & How frequently you monitor micro-albuminuria? & $3(2.88)$ & $47(45.19)$ & $54(51.92)$ \\
\hline 7 & How frequently you monitor lipids in your diabetic patients? & $16(15.38)$ & $37(35.58)$ & $51(49.04)$ \\
\hline
\end{tabular}




\section{Discussion:}

Over the decades, substantial progress is observed in the understanding, management, diagnostic criteria, and treatment armamentarium of T2DM. Upgrading the knowledge of the physicians can effectively improve the management of T2DM in medical practice. However, previous studies in different countries have shown the lack of utilization of these developments by primary care physicians. ${ }^{9-11}$ The present study aimed to evaluate the knowledge, attitude, and practice of MOs in rural PHCs regarding T2DM. Many of the MOs were not aware of the epidemiological and etiological burden in the management of T2DM. However, the MOs had considerable information about the diagnostic, therapeutic, and non-therapeutic interventions regarding T2DM.

Epidemiological knowledge of diabetes is important for rational planning and allocation of resources. ${ }^{2}$. Risk factors for development of T2DM, plasma glucose values for diagnosing T2DM, and criteria for prediabetes were recognized by few MOs. Diagnosing pre-diabetes is important as the interventions prevent or delay the occurrence of T2DM. ${ }^{5,12}$ Many randomized control trials have shown that T2DM can be prevented by life style modifications in individuals with prediabetes. ${ }^{13,14}$ Thus, lack of knowledge of prediabetes may be contributing to the rising prevalence of T2DM. The need of glycemic control is to prevent diabetes associated complications. However, only one participant had the knowledge of all the microvascular and macrovascular complications of T2DM. Knowledge of newer anti-diabetic medication is important for better management of T2DM. Very few MOs were aware of diabetes medications other than Insulin, sulfonylureas and metformin. None of the participants named incretin-based medications for diabetes. Progression of T2DM can be delayed but cannot be halted by oral medications. Thus, eventually insulin is required by many patients. Many times, insulin prescription is delayed due to anxiety of patients about injection, patient's cognitive abilities, and complexity of training patients to administer insulin, concerns of hypoglycemia, and weight gain. ${ }^{15}$ Many doctors in previous studies felt that use of insulin therapy is challenging. ${ }^{10}$ Response was similar in the present study also. But substantial number of MOs felt comfortable with using the insulin.

One of the requirements for managing T2DM is to affirm appropriate investigations to diagnose T2DM and monitor the glycemic control. Good number of participants used correct tests for diagnosing T2DM, however, urine glucose was the most commonly used test to diagnose T2DM, although not recommended. Its frequent use may be due to the low cost and easy availability in PHCs. Not many were confident in prescribing anti-diabetes medications. Almost half of the participants did not name any medication they prescribe for T2DM. Monitoring of $\mathrm{HbA} 1 \mathrm{c}$, lipid profile, and micro-albuminuria was not done according to recommendations by majority of participants. $\mathrm{HbAlc}$ is the important diagnostic criteria to assess the glycemic control and the effect of the treatment interventions. It appears to be due to lack of availability of these tests in the PHCs and the high cost. HbA1c assay is an important test both to diagnose T2DM and monitor the glycemic control. There is evidence that even in developed countries HbAlc is being underutilized. ${ }^{10}$

This study highlights the deficiencies in knowledge, attitude and practices of MOs towards management of T2DM. There is scope for improvement. Continuing professional development programs are fundamental to the development and maintenance of physicians' competencies. ${ }^{16}$ Doctor to population ratio in India is 1:1800, which is very low compared to the recommendations. ${ }^{18}$ Each MO must look after a larger population compared to the international standards. Therefore, the time spent on acquiring knowledge and updating skills is compromised. So new strategies and training methods have to be developed which can be incorporated within the time frame of MOs' schedule.

\section{Conclusions:}

The medical officers had considerable knowledge and attitude about T2DM, however due to lack of facilities at the PHCs, the practice of MOs in the management of T2DM is poor. Education programmes to expand the understanding of the MOs regarding T2DM and initiatives to advance the facilities at PHCs are essential to reduce the health burden, prevalence, and development of T2DM in developing countries, such as India. Further studies must be performed to evaluate the KAP of patients and other population regarding T2DM and other major NCDs.

\section{Conflict of interest: None.}

\section{References:}

1. United Nations. The future we want. Yew York: United Nations, 2012. http://sustainabledevelopment.un.org/ futurewewant.html (accessed Jan 14,2013).

2. Wild S, Roglic G, Green A, Sicree R, King H.Global prevalence of diabetes: estimates for the year 2000 and projections for 2030. Diabetes Care 2004;27:1047-1053.

3. Patnaik PK, Jain KK, Chandra P, Pathak J, Raman KV, Shah A. Diabetes in India: Measuring the dynamics of a public health catastrophe. Journal of Social Health and Diabetes 2016;4(2):77. 
4. Herath HM, Weerasinghe NP, Dias H, Weerarathna TP. Knowledge, attitude and practice related to diabetes mellitus among the general public in Galle district in Southern Sri Lanka: a pilot study. BMC public health 2017;17(1):535.

5. UK Prospective Diabetes Study (UKPDS) Group. Intensive blood-glucose control with sulphonylureas or insulin compared with conventional treatment and risk of complications in patients with type 2 diabetes (UKPDS 33). Lancet 1998;352:837-853.

6. Lindström J, Louheranta A, Mannelin M, Rastas M, Salminen V, Eriksson J, et al. The Finnish Diabetes Prevention Study (DPS): Lifestyle intervention and 3-year results on diet and physical activity. Diabetes care 2003;26(12):32303236 .

7. Ramachandran A, Snehalatha C, Mary S, Mukesh B, Bhaskar $\mathrm{AD}$, Vijay $\mathrm{V}$. The Indian diabetes prevention programme shows that life style modification and metformin prevent T2DM in Asian Indian subjects with impaired glucose tolerance (IDPP-1). Diabetologia 2006;49(2):289-297.

9. Shera AS, Jawad F, Basit A. Diabetes related knowledge, attitude and practices of family physicians in Pakistan. J Pak Med Assoc 2002;52:465-470.

10. Murray S, Lazure P, Schroter S, Leuschner PJ, Posel P, Kellner T, et al. International challenges without borders: a descriptive study of family physicians' educational needs in the field of diabetes. BMC Fam Pract 2011;12:27.

11. Khan AR, Al Abdul Lateef ZN, Khamseen MB, Al Aithan MA, Khan SA, et al. Knowledge, attitude and practice of ministry of health primary health care physicians in the management of type 2 diabetes mellitus: a cross-sectional study in the Al Hasa District of Saudi Arabia, 2010. Niger J Clin Pract 2011;14(1):52-59.

12. Pan XR, Li GW, Hu YH, Wang JX, Yang WY, An ZX, et al. Effects of diet and exercise in preventing NIDDM in people with impaired glucose tolerance. The Da Qing IGT and Diabetes Study. Diabetes Care 1997;20(4):537-544.

13. Tuomilehto J, Lindstrom J, Eriksson JG, Valle TT, Hamalainen H, Ilanne-Parikka P, et al. Prevention of type 2 diabetes mellitus by changes in lifestyle among subjects with impaired glucose tolerance. N Engl J Med 2001;344(18): 1343-1350.

15. Riddle MC. The underuse of insulin therapy in North America. Diabetes Metab Res Rev 2002;18(Suppl.3):S42S49.

16. Miller SH, Thompson JN, Mazmanian PE, Aparicio A, Davis DA, Spivey BE, et al. Continuing medical education, professional development, and requirements for medical licensure: a white paper of the Conjoint Committee on Continuing Medical Education. Committee on Continuing Medical Education. Journal of Continuous Education in the Health Professions 2008;28(2):95-98.

17. Karnataka Medical Counselling, Continuing Medical Education (CME). (Accessed on 22/Jan/2014). Available from http://karnatakamedicalcouncil.com/cme_wing.php.

18. Rural Health Statistics in India 2011. [accessed on October 8, 2012]. Available from: http://nrhm-mis.nic.in/UI/RHS/ RHS\%202011/RHS\%202011\%20Webpage.html. 